\title{
Medo, perplexidade, negacionismo, aturdimento - e luto: afetos do sujeito da pandemia
}

Fear, perplexity, negationism, consternation - and grief: affects of the subject during the pandemic

\author{
Marco Antonio Coutinho Jorge*1, \\ Denise Maurano Mello*2, \\ Macla Ribeiro Nunes*3
}

Este artigo pretende refletir sobre as falas dos sujeitos em tratamento psicanalítico durante a pandemia de COVID-19 pelo novo coronavirus (SARS-CoV-2) e, para tanto, elegeu alguns significantes que se impuseram à escuta dos psicanalistas ao longo do tempo.

Palavras-chave: Psicanálise, pandemia, medo, perplexidade, negacionismo

*1,3 Universidade do Estado do Rio de Janeiro - UERJ (Rio de Janeiro, RJ, Brasil).

*2 Universidade Federal do Estado do Rio de Janeiro - UNIRIO (Rio de Janeiro, RJ, Brasil). 
Assim como os serviços de delivery, que já tinham invadido a vida nas grandes cidades, uma das poucas atividades que prosseguiu existindo desde o início da pandemia da COVID-19, e ao que parece com mais força ainda, foi o atendimento psicanalítico. Contudo, no início do confinamento, por volta de 15 de março de 2020, data que marcou a população brasileira de modo nitidamente traumático, certo número de pacientes que estavam em tratamento (talvez um terço ou um quarto deles), resistiu a prosseguir por meio das sessões online (Skype, WhatsApp, telefone etc.).

Desses, alguns retornaram aos poucos ao tratamento na medida em que o confinamento foi se estendendo sem qualquer previsão possível de término. Outros, mesmo assim não o fizeram. A maioria, alegando um motivo tão legítimo quanto inédito para interromper o tratamento temporariamente: a falta de privacidade para realizar as sessões em sua residência, seja por falta de espaço para se isolar, seja até mesmo por falta de conforto psíquico para falar livremente no espaço caseiro. $\mathrm{O}$ imperativo categórico do confinamento geográfico — "Não saia de casa" - estendeu-se até o espaço mental e interrompeu ali também a liberdade: "Não saia de dentro de si". Talvez haja aí uma compreensível recusa inconsciente em introduzir o estranho (Unheimlich) no âmbito do lar e do familiar.

No curso de uma análise - nomeada também por Jacques Lacan como experiência analítica - , analista e analisando estão conjuntamente submetidos ao real do inconsciente onde e como quer que estejam. No confinamento, essa experiência nos coloca diante de outras dimensões do sujeito que podemos designar como "sujeito da pandemia". 


\section{ARTIGOS}

\section{Liberar a fala no confinamento}

A experiência psicanalítica é uma experiência da palavra e a clínica analítica foi criada pelo acionamento do dispositivo de liberação da fala pela via da regra fundamental, que prescreve que o analisando fale tudo o que lhe vier à cabeça, sem qualquer restrição e censura: "É por ter podido dizer aquilo que jamais havia conseguido enunciar que a histérica se cura" (Chemama, 1995, p. 197). Trata-se, na análise, de associar livremente para trabalhar com as ressonâncias desse dizer e evidenciar a expressão de conflitos existentes entre diferenças que nos habitam — das mais tênues às mais abomináveis, radicais e difíceis de serem conjugadas.

A clínica opera no âmbito do privado, trabalhando essencialmente com isso. É surpreendente que a pandemia nos evidencie que a psicanálise, sendo uma prática construída em torno daquilo que é mais privado - o sigilo analítico é a sua chave de segurança - não possa ser exercida em alguns casos até mesmo na privacidade do lar. Mas é também compreensível que a antítese entre liberdade de fala e confinamento se apresente como excessiva e intolerável.

Eventos pontuais se sucedem e anunciam a chegada do inesperado, quando a epidemia é rapidamente rebatizada como uma pandemia. Alguém relembra: "Minha avó contava que, com a gripe espanhola, carroças com pilhas de cadáveres circulavam nas ruas...". Simultaneamente, na TV o repórter diz que faltam não apenas leitos para cuidar dos enfermos, mas que igualmente, dado o número de mortos pelo vírus, o cemitério já não tem mais como enterrá-los. Um WhatsApp comunica o falecimento do marido de uma amiga e você, ao descobrir que esteve próximo de alguém que teve diagnóstico positivo, já começa a apresentar sensações e sintomas em cadeia. Uma notícia aqui, um comentário ali, um achado nas redes sociais, a contaminação de nossa existência prolifera como um tsunami. Até o ar que respiramos fica infectado, ainda que não seja pelo coronavírus, mas pela espreita da morte e da miséria que se alastra. Há o medo de contrair a doença que compete com outro medo onipresente: o de que pessoas que amamos contraiam a doença. Estamos acuados em casa, tornada uma prisão domiciliar, com a morte rondando lá fora, pronta para nos fisgar. De súbito, a preservação da vida exigiu seu confinamento.

Este artigo pretende refletir sobre as falas dos sujeitos em tratamento psicanalítico durante a pandemia e, para tanto, elegeu alguns significantes que foram se impondo à escuta dos analistas ao longo do tempo. 


\section{Medo}

Quando certa feita um jornalista indagou a Lacan por que ele achava que as pessoas buscavam tratamento analítico, ele respondeu, com uma resposta que impressiona por sua simplicidade e concisão: "Por medo".

O termo medo não é muito comum nos estudos de psicanálise, onde ele é comumente recoberto por seu afeto gêmeo, a angústia, esta sim, onipresente nos trabalhos teóricos e clínicos. Desde as descobertas de Sigmund Freud sobre o inconsciente, feitas na língua alemã na qual a palavra angst designa tanto o medo quanto a angústia, esse recobrimento se tornou familiar aos estudiosos da mente. Talvez devido a essa ambiguidade inarredável do termo angst em sua língua materna, Freud tenha se esmerado em produzir sua investigação sobre a angústia - uma das três figuras clínicas mais emblemáticas, junto com os sintomas e as inibições — desembaraçando-se dessa homogeneização e definindo ambos os afetos — medo e angústia - numa relação de mútua referência: se o medo apresenta um objeto definido - tem-se medo de algo, um bicho, um lugar, uma pessoa - , a angústia é um afeto similar cujo objeto, contudo, não sabemos designar. Ela é um aperto no peito, um sufocamento, uma sensação corporal indefinida e impossível de ser nomeada. Resta falar para dar limites a esse buraco que arrisca tragar o sujeito.

No confinamento provocado pela COVID-19, os pacientes falam do medo incessantemente, especialmente do medo da morte, a própria e a dos entes queridos. É incrível que na pandemia o medo da contaminação pelo vírus, esse enigmático inimigo da vida humana, surge quase indistinguível da angústia: pois há o objeto que se teme, mas onde está ele? A invisibilidade do vírus esvanece o objeto que se teme e ao mesmo tempo o torna onipresente, produzindo o sufocamento característico da angústia. Quando medo e angústia se homogeneizam, prestando-se a uma inédita confusão afetiva, os sujeitos reagem de formas diferentes: com perplexidade, negacionismo ou aturdimento.

\section{Perplexidade}

Essa palavra resume uma série de enunciações dos pacientes aprisionados em seus domić́lios por uma ameaça tão invisível quanto temerária. Ela é o motor da frase mais pronunciada por eles: "Eu jamais imaginei que iria viver uma coisa dessas". 
Ela está oculta nos rituais obsessivos que se tornaram universais e necessários: lavar as mãos, não tocar no rosto, usar álcool gel continuamente, lavar os alimentos, higienizar qualquer objeto que venha do mundo externo, despojar-se imediatamente de toda peça do vestuário que tenha sido usada fora de casa, e sobretudo, não tocar no outro, fonte possível de contaminação e morte.

$\mathrm{O}$ alien do exterior não pode ser introduzido na aeronave sob pena de pôr a viagem a perder. Os olhos se arregalam para tentar apreender o inapreensível, ver o invisível e o que resta é a sensação de que, como o verdadeiro alien é fugidio e tem a proteção insuperável da invisibilidade, todos aqueles que se encontram a bordo são vigiados por todos os outros. Tudo pode trazer o agente destrutivo invisível para o interior e nenhum ritual parece ser suficiente para o sujeito se assegurar de suas medidas protetoras. A obsessão é a regra, o cansaço extenuante o efeito, a perplexidade o afeto.

A perplexidade se apresenta quando a nova realidade parece mimetizar uma obra de ficção científica, quando a comunicação virtual entre as pessoas se impõe como regra inabalável e a ausência de contato físico uma restrição inequívoca; quando um dos elementos mais idiossincrásicos de nossa existência, o fato de sermos seres sociáveis, pode ser letal; quando as expressões de amor que salvam, também podem matar; quando a manutenção da mais estrita solidão é a salvação.

Nesse mundo convulsionado pela realidade tornada subitamente irreal, o sonho passa a ser invocado todas as noites e tudo indica que será nele que um pouco de realidade poderá ser reconstituída. Com frequência, os analisandos passam a narrar sonhos como nunca o fizeram e buscam o sentido do que está se passando com eles no inconsciente. Surgidos aos borbotões, os sonhos revelam que, alterada a consciência em sua homeostase mínima, abalada a percepção em sua figuração do mundo, resta ao inconsciente paradoxalmente constituir a reserva natural, o esconderijo onde algo de reconhecível tenha sido preservado.

Se, como indicou Alain Didier-Weill, com frequência no trabalho do sonho o inconsciente visa dar uma resposta a uma pergunta que ficou sem resposta para o sujeito durante o dia — pois como salientou Lacan, o inconsciente é um trabalhador encarniçado e trabalha tanto que até quando vamos dormir, cansados, ele continua trabalhando - , o sujeito da pandemia parece elaborar no sonho, paradoxalmente, a fórmula certeira para reinventar a realidade, tornada abjeta e insuportável.

O real, diz Lacan insistentemente, é o que não tem nenhum sentido, é a falta de sentido, é o sentido em branco e para sabermos que estamos diante de 
algo da ordem do real - no sentido lacaniano do termo, isto é, algo que é totalmente diverso da realidade e não se confunde com ela - é necessário que esse algo não possua nenhum sentido. A realidade é invenção, criação, ficção - em resumo, fantasia. O sonho, esse também não deixa de sê-lo: "Coleridge deixou escrito que as imagens da vigília inspiram sentimentos, ao passo que no sonho os sentimentos inspiram as imagens [...] Se um tigre entrasse neste quarto, sentiríamos medo; se sentimos medo no sonho, engendramos um tigre...", diz Jorge Luis Borges (1976, p. 5) nos chamando a atenção para o pesadelo.

A perplexidade desencadeia, por sua vez, as crenças delirantes que pretendem dar sentido ao real sem sentido. Teorias conspiratórias formigam rapidamente para explicar o que parecia inexplicável e tentar descobrir culpados pela infestação: bioterrorismo americano contra os chineses, aproveitando-se do acolhimento nos Jogos Militares de outubro de 2019 em Wuhan? Ou seu oposto: vírus produzido na China para dar um golpe de mercado?

Mesmo o discurso da ciência, ao qual o sujeito tem que se agarrar, sobretudo nesse momento de tamanha perplexidade, impõe tarefas irrealizáveis. Interessante lembrar a assertiva de Lacan (1973-74): "O discurso da ciência tem consequências irrespiráveis para o que se chama humanidade. A psicanálise é o pulmão artificial com a ajuda do qual tentamos assegurar o que é preciso de gozo no falar, para que a história continue" (p. 7). Nessa perspectiva, desempenhamos uma função compensatória, trabalhamos para que não falte ar, invocando as palavras que, nesse momento, ganham ares divinatórios. Efetivamente, operamos para que o ar passe, a palavra circule, e o peso excessivo de toda generalização - que sepulta o sujeito singular e lhe subtrai o gozo - , possa lhe ser restituído pelo poder transfigurador da fala, permitindo-lhe o acesso a uma cota de solução singular para suportar o momento presente, e manter-se, efetivamente, vivo. Mas, é verdade que, por motivos diversos, nem todos têm acesso a esse recurso.

\section{Negacionismo}

Quando a realidade é invadida pelo desconhecido ela se torna irreal e o medo pode nos fazer pura e simplesmente negá-la. A negação é a máscara retirada do rosto e posta, como um poderoso véu, no mundo; uma forma de escapar de uma verdade desconfortável, dolorosa ou mesmo insuportável. 


\section{ARTIGOS}

Ela é o índice oculto do desespero desencadeado pela constatação da extrema precariedade a que a humanidade pode ser lançada subitamente.

Não à toa muito ouvimos falar dos movimentos que - a despeito da consistência de fatos vividos, historicamente comprovados e testemunhados - negam o horror dos campos de concentração e a Aids. Ao longo da pandemia, a negação às vezes se revela de forma branda quando o sujeito afirma: "Parei de ver os noticiários". Observa-se, assim, em certos segmentos da população, insuflada pela propaganda alienante contínua despejada pelos órgãos oficiais, uma tendência nada rara de minimizar ou até mesmo desprezar o poder patogênico e mortífero do vírus; de inventar curas mágicas através de substâncias comprovadamente ineficazes para seu tratamento. Tudo se passa como se, na impossibilidade de crer na realidade inassimilável e traumática da letalidade do vírus, só nos restasse recorrer a uma substância sem nenhum efeito comprovado e desafiar infantilmente esse veneno oculto com uma poção mágica. Aqui, a minimização dos fatos, o desprezo e a impossibilidade de crer na realidade que insiste em se apresentar como irrepresentável, também afirmam seu parentesco com a crença delirante.

Como mostra Alain Didier-Weill, evocar o termo crença introduz dois problemas correlatos que vale pontuarmos: a vizinhança entre ciência e psicanálise, assim como a vizinhança entre crença delirante e crença não delirante. Essa correlação também se deve à foraclusão que ciência e psicose estabelecem sobre o sujeito do inconsciente. Aliás, é curioso que Freud tenha abordado a questão da crença no inconsciente de maneira indireta, por meio da descrença que, segundo ele, seria constitutiva do discurso paranoico, aquele que também o atinge quando, fascinado pela Acrópole, se dá conta de que não consegue acreditar no que vê. Como assevera Didier-Weill (1997), em sua estrutura de desconhecimento paranoico do inconsciente, o Eu é aquele que diz: "Eu o vejo, mas não creio nele" (p. 111). Nesse caso, "crer nele" se refere ao ato psíquico pelo qual o sujeito não se desvia do furo no saber, incognoscível, que é o real do inconsciente. Ao contrário, volta-se para ele segundo um ato de não descrença que não deixa de estar balizado no "sim" fundamental que Freud nomeou de Bejahung.

Mas a realidade dos sujeitos é atingida simultaneamente por outra via, igualmente virulenta: o negacionismo instituído, desde o império de fake news produzidas pela máquina estatal até a negação da gravidade da pandemia, considerada desde o início uma virose banal. Mas ele não impede que as mortes diárias atinjam um número aterrador. 


\section{Aturdimento}

Tudo indica que nossa civilização está recebendo de uma só vez a conta, acumulada em décadas e com juros, da negação do perigo inerente ao não reconhecimento de nossa vulnerabilidade e nosso pertencimento a um todo orgânico e interdependente. Quisemos crer que fechados em condomínios, carros blindados, assegurados por cargos prestigiosos, ações na bolsa, reservas financeiras, palácios privados, títulos, influências políticas, informações privilegiadas, conhecimentos, suplementos vitamínicos, aparelhos tecnológicos, circuitos de deslocamento protegidos - tudo o que ajudou a alimentar um selvagem império do valor do capital em detrimento do valor da vida, e que atuou até mesmo em nome de hipocritamente "garanti-la" estaríamos salvaguardados. Ocorre que a expansão mundial da pandemia de COVID-19 começou pelas idas e vindas dos mais abastados, supostamente os mais protegidos.

Em nosso país, a saúde mental e física dos brasileiros é posta à prova a cada dia, quando temos que suportar o massacre traumático da pandemia associado à ignomínia de um governo mortífero em todas as suas esferas, em cujo Ministério da Educação desfilam vociferantes representantes da ignorância crassa. Governo no qual o ministro da cultura invoca a estética nazista como o ideal a ser erigido; no qual o ministro do meio ambiente se pronuncia cinicamente contrário aos objetivos universalmente reconhecidos de seu cargo; no qual o ministro das relações exteriores provoca repetidamente problemas diplomáticos e comerciais para o pais; no qual o ministro da justiça acompanha o presidente para atos aviltantes em relação à própria democracia que o elegeu; e no qual, last but not least, em plena pandemia, com graves consequências tanto para a saúde quanto para a economia, o governo decapita o ministério da saúde de uma liderança médica segura em favor de uma tutoria militar cientificamente analfabeta.

Atônitos, vemos desfilar diante de nossos olhos, não um projeto de construção de um país, não a eleição de um caminho a seguir rumo a um ideal de Estado no horizonte. Assistimos no Brasil de hoje um ataque feroz e cotidiano a todos os ideais de civilidade. O politicamente correto tornou-se obsceno e, a obscenidade, o pão nosso de cada dia. Trata-se de destruir tudo o que se encontra edificado. Eis aí o único objetivo detectável numa série de posturas e medidas governamentais com consequências nefastas como o genocídio dos povos indígenas, o aprofundamento das desigualdades sociais, o extermínio das comunidades carentes, a devastação da floresta amazônica, 


\section{ARTIGOS}

o desmonte das universidades públicas e das instituições culturais, do ensino básico, dentre outras atrocidades.

Nesse quadro de destruição, não surpreende que a política de saúde ceda à política da doença. Se os mais vulneráveis à letalidade da COVID-19 são os idosos e os já debilitados — mas "E daí...?" —, afinal suas mortes desoneram os cofres públicos, acabam por contribuir com a dita reforma previdenciária. De forma similar, a liberação da produção e comercialização de armas e munições, faz todo sentido na política do gozo que busca e celebra a morte (Salles, 2020).

De acordo com a compreensão psicanalítica, não se trata de aspirar por sociedades ideais, nas quais ódio, injúria e ignomínia não compareçam. A psicanálise é fruto da dura constatação de que o conflito é inerente ao funcionamento psíquico e a imbricação entre pulsões de vida e de morte, assim como a íntima relação entre o amor e a destruição, inarredáveis. Tal constatação é o que justifica Freud ter teorizado que o psiquismo não se orienta só pelo prazer, mas também por ir mais além dele, sendo regido por forças bem obscuras.

Nosso aturdimento se potencializa quando vemos diante de nós se descortinar um cenário político que advoga a desimbricação pulsional. Como se as forças do amor cedessem aos gabinetes do ódio, repartindo o mundo, e particularmente o país, em dois universos incomunicáveis: os aliados, que devem viver, e todo o resto, que deve ser exterminado, física e moralmente. Que isso se dê nesse cenário pandêmico — no qual um vírus que nem vivo é, dado que precisa da vida alheia para cumprir seu automatismo de destruição; e que se exija de nós, que nos finjamos de mortos, confinados em nossos quadrados, não é irrelevante psiquicamente. Não há como não ser afetado. Cada um, conforme sua estrutura defensiva, reage com um estilo próprio.

Um analisando sexagenário, por exemplo, após quatro meses de isolamento social praticamente total, dentro de casa e sem contato nenhum com o mundo externo - seguindo à risca a recomendação de seu médico, que logo nos primeiros dias de eclosão da pandemia decretou "Não saia de casa" - escreveu um texto que reflete a desconexão provocada pela pandemia nos sujeitos em relação a seus próprios afetos: "É estranho não saber o que se está sentindo, quando tanta emoção está presente no mundo. Quais são os afetos que mais afetam a todos agora? Há sobretudo a presença de uma dor crescente, a dor dos que perderam entes queridos. Esses afetos coexistem e nos deixam perplexos, ainda mais quando nos damos conta de que não sabemos onde isso tudo vai dar. Mas creio que consegui detectar em mim, após muito refletir, qual o afeto que mais me invade. É a saudade de tudo. E sinto que a morte do Aldir Blanc hoje me ajudou a entender isso. Sinto saudade de tudo. É uma 
saudade estranha, diferente de quando se sente saudade de alguém ou de algo. É saudade de tudo mesmo. Talvez por causa dessa saudade toda é que tenha me voltado para o arquivo de fotos: fotos antigas, de viagens, fotos das quais não me lembrava mais. Na falta de ver o mundo no presente, a volta às visões passadas é requerida. Saudade até do que não conheço. Me dou conta, ao final, de que saudade de tudo significa no fundo saudade da vida".

Nesse momento, assistimos atônitos à realização do que Raul Seixas cantou em $O$ dia em que a Terra parou: "Essa noite eu tive um sonho / de sonhador / Maluco que sou, eu sonhei / com o dia em que a Terra parou.../ Naquele dia, ninguém saiu de casa, ninguém"... Curiosamente, ele finaliza a canção dizendo: "No dia em que a Terra parou / Eu acordei / No dia em que a Terra parou / justamente / No dia em que a Terra parou / Eu não sonhei, acordei / No dia em que a Terra parou...". Que o despertar encontre lugar, é tudo que podemos desejar para que a vida possa ser reinventada em outra direção. Despertar - um dos efeitos mais ambiciosos visados pela psicanálise no que diz respeito à atividade fantasística inconsciente - nesse caso, significaria o trabalho forçado da reinvenção de nossos hábitos, das relações pessoais e familiares, dos modelos de trabalho, de nossa economia e sistemas políticos, desde a mera organização sanitária até a mais complexa relação com as ideologias.

\section{O freio da roda do tempo}

Na quarentena, o termo "latência" assumiu lugar preponderante no vocabulário dos músicos para designar o atraso no tempo de transmissão que impossibilita radicalmente a prática musical em conjunto. A riqueza dos aparatos tecnológicos aos quais se tem acesso permite gravar, editar e compartilhar as produções musicais, mas, de maneira geral, pararam os ensaios de orquestra, pararam os grupos, bandas, coros. Certo registro do tempo parou para os músicos. Restou, todavia, para esses seres que também existem no imaterial e no inaudito do tempo, compartilhar um tempo virtual, insistir e criar.

Freud, por sua vez, designou como "período de latência" o tempo de pausa que vai do declínio da sexualidade infantil até o início da puberdade. Uma pausa barulhenta: tempo de uma verdadeira movimentação de investimentos, desinvestimentos e reinvestimentos afetivos, sexuais, morais e estéticos na constituição da sexualidade do sujeito. De modo geral, o estado de latência remete a um período durante o qual algo se elabora, antes de assumir existência efetiva. Estaríamos nós vivendo um tipo de latência? 
Chamando atenção para a questão do vazio e do enigma, Claude Rabant (1997) indaga de que modo podemos tomar em consideração essas outras dimensões que ligam a análise às práticas artísticas, "práticas de invenção sem modelo" (p. 48). Como podemos encontrar, no que diz respeito aos objetos voz e olhar, por exemplo, novos modos de intervenção? Rabant faz a hipótese de que existem nas práticas artísticas certas reservas de revolta das quais necessitamos; e o ponto comum dessas práticas está justamente numa certa relação com o vazio que, inclusive, as oporia ao "demasiado-pleno" sem volta dos objetos da tecnização desenfreada - e suas decorrentes misérias - a qual estamos tão acostumados, por muitas razões, a criticar.

Agora, a aceleração excessiva parou. De certa maneira, a roda do tempo foi freada e desacelerou. Certamente que uma outra forma de aceleração está em curso, mas, com o psicanalista, sabemos que de qualquer modo temos que trabalhar em torno do sentimento de certo perigo, que Nietzsche já relacionava às consequências do que chamou de "nosso mito que desaparece"; e, aqui, os filósofos, a arte e os psicanalistas, tomariam o lugar e o duro destino de ser o mito que está em desaparição. Nesse sentido, é preciso, no entanto, poder explorar esse mito e, na impossibilidade de restaurar sua origem, descamar seus restos e interrogar as figuras de sua desaparição como figuras que são de nossa própria finitude e precariedade.

Nessa perspectiva, não seria para uma forma suntuosa e soberba de arte que iríamos nos voltar, mas para suas formas mais simples e mais extremas nas palavras de Claude Rabant, formas de "pôr limites a nu", pois é a partir desses limites que a esperança pode retomar vigor. Nesse espaço errante, fronteira entre o dentro e o fora da viabilidade de escrita do momento em que vivemos, há "decisões de leitura" a tomar que têm a ver com a arte e, por isso, significam que é uma "leitura-para-além" (Rabant, 1997, p. 51).

Paradoxalmente, o "não sair de dentro de si" ao qual estamos todos assujeitados neste momento, viabiliza não colocar outra coisa senão o próprio corpo como espaço de respiração — não sem certo sufocamento — entre o domínio da realidade e o impossível de inscrever, entre o presente suspenso e o futuro sem nome. O "não sair de dentro de si" também pode significar, diríamos com Alain Didier-Weill, realizar um ato de confiança e de fé que nos libera da descrença incauta e nos possibilita a capacidade de transferir para uma alteridade situada em uma extensão ainda não existente, isto é, o endereçamento ao que ainda não está aqui, mas que pode vir a estar.

De súbito, com o despertar, uma consciência planetária se adensaria pela experiência radical de um contágio que revela que estamos todos 
ameaçados. Pois no reino do coronavírus, não há diferenciação entre branco, negro, amarelo ou vermelho. Estamos todos igualmente roxos de medo, humanamente vulneráveis quando nosso corpo se torna um alvo fácil de um invasor desconhecido. Nesse reino, também não se distingue gênero, tampouco opções sexuais, ideológicas, condições financeiras, nele se transpõe até mesmo fechamento de fronteiras. O mundo se revela sem fronteiras, como cantava John Lennon em Imagine, ainda que isso nos seja escancarado pela pior via, a da destruição incoercível e sem limites.

Talvez o dano trazido pela pandemia, malgrado sua extensão, não seja suficiente para promover um trabalho urgente e efetiva transvaloração na sociedade contemporânea de modo a torná-la mais justa, e o planeta mais sustentável. Bem sabemos que o compromisso civilizatório, longe de visar um mundo ideal onde só o bem vigore, demanda uma nodulação entre forças construtivas e destrutivas, já que umas não vão sem as outras.

Diante disso, a psicanálise sempre trabalhará incansavelmente para minar a crença nas verdades totalizantes, nas soluções universais, na disciplina cega, abrindo brechas, mantendo sempre um furo, um vazio vitalizante por onde o ar circule e a respiração se dê. Não à toa ela ganha muito destaque neste período de confinamento, isso sem falar na sobrecarga de luto de tantas perdas que está por ser feita.

Agradecimentos: Os autores agradecem a Arthur Teixeira Pereira pela formatação da versão final do texto.

\section{Referências}

Borges, J. L. (1976). Livro dos sonhos. Buenos Aires, AR: Torres Aguero Editor S.R.L.

Chemama, R. (1995). Dicionário de psicanálise. Porto Alegre, RS: Artes Médicas Sul.

Didier-Weill, A. (1997). Por um lugar de insistência. In M. A. C. Jorge (Org.), Lacan e a formação do psicanalista. Rio de Janeiro, RJ: Contra Capa/Corpo Freudiano Seção Rio de Janeiro, 2006.

Lacan, J. (1973-74). Déclaration à France Culture. Le Coq-Heron, 46/47, 3-8.

Rabant, C. (1997). O vazio, o enigma. In A. Didier-Weill (Org.), Nota Azul. Freud, Lacan e a arte. Rio de Janeiro, RJ: Contra Capa.

Salles, J. M. (2020, julho). A morte e a Morte - Jair Bolsonaro entre o gozo e a morte. 


\section{ARTIGOS}

Revista Piaui, 166. Recuperado de: <https://piaui.folha.uol.com.br/materia/amorte-no-governo-bolsonaro/>.

\section{Resumos}

(Fear, perplexity, negationism, consternation - and grief: aspects of the subject during the pandemic)

This article aims to reflect on the discourses of subjects who are undergoing psychoanalytic treatment during the COVID-19 pandemic caused by the new coronavirus (SARS-CoV-2). To achieve that goal, we selected some signifiers which imposed themselves to the therapists' listening over time.

Key words: Affects, subject of the pandemic, confinement, discourse

(Peur, perplexité, négationnisme, étonnant et deuil: les affects du sujet de la pandémie)

Cet article entend réfléchir sur les discours des sujets sous traitement psychanalytique lors de la pandémie de COVID-19 par le nouveau coronavirus (SARS-CoV-2) et, à cet effet, a élu certains signifiants qui se sont imposés à l'écoute des thérapeutes au fil du temps.

Mots clés: Affection, sujet de la pandémie, accouchement, discours

(Miedo, perplejidad, negacionismo, aturdimiento y duelo: afectos del sujeito de la pandemia)

Este artículo pretende reflexionar sobre el discurso de los sujetos en tratamiento psicoanalítico durante la pandemia de COVID-19, ocasionado por el nuevo coronavirus (SARS-CoV-2) y, para ello, se eligieron algunos significantes que se impusieron a lo largo del tiempo a la escucha de los terapeutas.

Palabras clave: Afectos, sujeto de la pandemia, confinamiento, discurso

Citação/Citation: Coutinho Jorge, M. A., Mello, D. M., \& Nunes, M. (2020, setembro). Medo, perplexidade, negacionismo, aturdimento - e luto: afetos do sujeito da pandemia. Revista Latinoamericana de Psicopatologia Fundamental, 23(3), 583-596. http://dx.doi. org/10.1590/1415-4714.2020v23n3p583.9.

Editora/Editor: Profa. Dra. Ana Maria G. R. Oda e Profa. Dra. Sonia Leite

Submetido/Submitted: 18.8.2020 / 8.18.2020 Aceito/Acepted: 20.8.2020 / 8.20.2020 
Copyright: C 2009 Associação Universitária de Pesquisa em Psicopatologia Fundamental/ University Association for Research in Fundamental Psychopathology. Este é um artigo de livre acesso, que permite uso irrestrito, distribuição e reprodução em qualquer meio, desde que o autor e a fonte sejam citados / This is an open-access article, which permits unrestricted use, distribution, and reproduction in any medium, provided the original authors and sources are credited.

Financiamento/Funding: Este trabalho não recebeu apoio / This work received no funding..

Conflito de interesses/Conflict of interest: Os autores declaram que não há conflito de interesses. / The authors declare that there is no conflict of interest.

\section{Marco Antonio Coutinho Jorge}

Professor Associado do Instituto de Psicologia da Universidade do Estado do Rio de Janeiro - UERJ (Rio de Janeiro, RJ, Br); Diretor do Corpo Freudiano Escola de Psicanálise - Seção Rio de Janeiro; Doutor em Comunicação e Cultura pelo Programa de Pós-Graduação em Comunicação e Cultura da Universidade Federal do Rio de Janeiro - UFRJ (Rio de Janeiro, RJ, Br).

Rua Terezina, 19 - Santa Teresa

20240-310 Rio de Janeiro, RJ, Br

macjorge@macjorge.pro.br

https://orcid.org/0000-0002-0710-7527

Denise Maurano Mello

Professora Titular da Universidade Federal do Estado do Rio de Janeiro - UNIRIO (Rio de Janeiro, RJ, Br), atuando no Curso de Direito e no Programa de Pós-Graduação em Memória Social; Doutora em Filosofia pela Pontifícia Universidade Católica do Rio de Janeiro - PUC-RJ (Rio de Janeiro, RJ, Br) e pela Université Paris-Est Créteil Val-de-Marne - UPEC/França (Paris, França).

Avenida Bartolomeu Mitre, 410, cob. Leblon

22431-002 Rio de Janeiro, RJ, Br

dmauranomello@gmail.com

https://orcid.org/0000-0003-3498-3773

\section{Macla Ribeiro Nunes}

Doutoranda em Pesquisa e Clínica em Psicanálise pelo Programa de Pós-Graduação em Psicanálise da Universidade do Estado do Rio de Janeiro - PGPSA/UERJ (Rio de Janeiro, RJ, Br); Mestre em Teoria Psicanalítica pelo Programa de Pós-Graduação em Teoria Psicanalítica da Universidade Federal do Rio de Janeiro - UFRJ (Rio de Janeiro, RJ. Br). Avenida Jaime Poggi 99, B1. 03, apto. 1506 - Jacarepaguá

22775-130 Rio de Janeiro, RJ, Br

maclanunes@gmail.com

https://orcid.org/0000-0002-4082-2661

This is an open-access article, which permits unrestricted use, distribution, and reproduction in any medium for non-commercial purposes provided the original authors and sources are credited. 